\begin{tabular}{lllllll}
\hline Revista Iberoamericana. & Vol. LXV, Núm. 186 , Enero-Marzo $1999 ; \quad 59-80$ \\
\hline
\end{tabular}

\title{
HACIA LA DESCOLONIZACIÓN DE LA MIRADA GEOGRÁFICA: LAS PRÁCTICAS TERRITORIALES INDÍGENAS EN LA "PREHISTORIA" DE LA RIBERA NORTE DEL RÍO DE LA PLATA
}

\author{
POR \\ Gustavo Verdesio \\ Louisiana State University
}

La imagen del territorio americano como una "página en blanco", en la cual el visitante europeo haría impunemente su inscripción es, obviamente, una falacia (de Certeau, The Writting of History, xxv). A pesar de que la cartografía europea presenta las cosas de este modo, el hecho es que estas tierras llevaban más de diez mil años de inscripciones indígenas cuando llegó el primero de los exploradores. Por esta razón, algunos estudiosos han optado por investigar las representaciones cartográficas europeas en contrapunto con las que produjeron los propios indígenas, a fin de ofrecer una visión algo más equilibrada, menos sesgada, de la geografía colonial americana (De Vorsey; Mignolo, "Colonial Situations"). Como señalé en otro trabajo, se trata de una empresa necesaria, pero que plantea ciertos problemas ("Las representaciones" 148-149). Me refiero a que un estudio de esa naturaleza será posible sólo para aquellos casos en que las culturas indígenas analizadas hayan producido representaciones territoriales en materiales durables que, obviamente, hayan llegado hasta el presente. Esto quiere decir que muchas de las culturas que poblaron el continente quedarían excluidas de este tipo de proyecto, por no habernos legado "copias duras" (equiparables a mapas en la tradición europea) o, simplemente, por no haberlas producido nunca.

Surge, entonces, la inquietud sobre qué hacer en el caso de esas culturas sin "mapas". ¿Debe aceptarse la imagen (aunque sea falaz) de un territorio virgen donde las primeras inscripciones las hicieran los visitantes europeos? Creo que no. El hecho de que los indígenas de las culturas menos estudiadas (me refiero a la mayoría de las que quedan afuera de la tríada privilegiada en los estudios coloniales: Aztecas, Incas y Mayas) no tuvieran costumbre de realizar representaciones territoriales en materiales durables no significa que no fueran capaces de producirlas. Un testimonio de ello son los mapas elaborados para las relaciones geográficas (a pedido de la corona) donde el conocimiento del territorio provenía fundamentalmente de "indios viejos" (Mignolo, "La grafía, la voz"). De modo que, si era necesario, los indígenas eran capaces de ofrecer información sobre el espacio que practicaban. Partamos de la base, entonces, de que si todos los seres humanos son capaces de elaborar "mapas mentales", de imaginar y ordenar el espacio a través del cual se mueven, no hay razón para suponer que los aborígenes sean una excepción.

La falta de reliquias, de "copias duras," no debería desanimarnos en la empresa de reconstruir el complejo y variado universo de concepciones espaciales que se produjo 
durante el encuentro colonial. Por el contrario, creo que es posible intentar recuperar, en parte, las prácticas espaciales de los indígenas sin mapas, a través de las cuales se puede llegar a tener una idea de la forma en que concebían e imaginaban el territorio que habitaban. En otro trabajo sugerí algunas de las vías por las cuales esta empresa se puede llevar a cabo: la información provista por las crónicas y la evidencia arqueológica ("Las representaciones"). De esta forma será posible apreciar hasta qué punto la pretendida página en blanco que presenta la cartografia europea estaba ya inscripta por los aborígenes. Es decir, qué trazas sobre el territorio, qué itinerarios existían antes de la llegada del sujeto occidental. De lo que se trata, entonces, es de restituir algo de materialidad a esos pueblos que fueron, literalmente, borrados del mapa por la academia occidental. Conjuntamente a esta operación de exclusión, se produjo otra: su desaparición del continuum histórico. Representados como pueblos primitivos y salvajes, sin territorio ni cultura, se convirtieron en pueblos sin historia. El estudio de la espacialidad aborigen, entonces, puede ser también una herramienta para recordar su existencia, para recuperar su historicidad.

En el trabajo citado, me limité a sugerir las diferencias entre las representaciones territoriales indígenas y europeas basándome en las prácticas espaciales reconstruidas. El territorio en cuestión (ribera norte del Río de la Plata) aparecía entonces menos como una página en blanco que como una tela atravesada por una serie de filigranas de origen indígena. Pero es evidente que los grupos que habitaban ese territorio al tiempo de la llegada de los españoles no habían sido los primeros en practicarlo. Según la doctrina más recibida, los aborígenes del tiempo histórico (charrúas, chanáes, guaraníes) se habrían instalado en las tierras estudiadas en un momento bastante reciente: alrededor del $2000 \mathrm{AP}$ -antes del presente- (Pi Hugarte 55). De modo que muchos de los accidentes del terreno, su fauna, su flora, ya habían sido usados con anterioridad. Estas etnias (como los españoles, portugueses y demás europeos) tampoco operaron sobre una página en blanco, sino que se encontraron con un espacio ya habitado, ya inscripto. Los habitantes anteriores a las etnias históricas no sólo usaron el territorio, sino que también alteraron el paisaje, dejaron (efectivamente) marcas visibles, construcciones arquitectónicas, petroglifos y pictografias. Creo que es difícil ofrecer una visión general (una comprensión) de las prácticas espaciales que precedieron la llegada de los españoles si no tenemos en cuenta las que tuvieron lugar antes de la ocupación del territorio por parte de las etnias históricas. Son estas actividades prehistóricas las que en este trabajo se van a estudiar.

Hasta el día de hoy, la imagen del ser humano prehistórico en el territorio al norte del Río de la Plata, es la del salvaje (Peláez Castello 66). Esta concepción ha sido un pretexto para ignorarlo, es decir, para no estudiarlo (Cabrera, "Presentación" 223). De este modo es que se los borra del territorio y se fomenta la mencionada imagen de la página en blanco. Pero como decía más arriba, también se los elimina de la historia, no sólo por carecer de letras (lo que le veda el acceso a aquélla, que es letrada por definición) sino porque no merece la pena como objeto de estudio (de historización). Sin embargo, a pesar de la olímpica ignorancia de los estudiosos, esos pueblos existían y actuaban sobre el territorio. De ese modo dejaron huellas y señales, privilegiando ciertas regiones y señalándolas. Esas huellas de actividad fueron no sólo percibidas sino también utilizadas por las etnias del tiempo histórico, como tendremos oportunidad de ver. 
Según el arqueólogo López Mazz, no puede entenderse la sociedad presente si no se hace un esfuerzo por incorporar el pasado indígena (histórico y pre-histórico) a la matriz cultural en la que está inserto el estudioso ("La reconstrucción del pasado" 169). Cabrera sostiene algo similar: que el estudio de la historia americana nativa es fundamental para entender la historia colonial ("El indígena y la conquista" 100). El argumento de López Mazz está relacionado, de alguna manera, con el de Rodolfo Kusch, quien intentando recurrir a las raíces aborígenes, se rehusaba a la simple "exhumación científica" del pensamiento indígena (Kusch, "El pensamiento" 11). En su lugar proponía "rescatar" un estilo de pensar, tarea que presupone, según Mignolo, "ciertos puntos de apoyo, que no sean, precisamente, las raíces y los puntos de apoyo que dieron lugar a la configuración de estilos de pensar entre los cuales se cuenta la posibilidad de exhumar científicamente otros estilos de pensar" ("Occidentalización" 33). Es decir, lo que se proponen tanto Mignolo como Kusch es entender ese pasado cultural desde una perspectiva que no lo represente meramente como material etnográfico, sino como formas de pensamiento en su propio derecho. Lo que postula López Mazz (y lo que intenta este trabajo) está en una línea similar a la de los estudiosos citados, sólo que el objeto a recuperar no es el pensamiento en general, sino una de las formas en que se manifiesta: el conocimiento del espacio y la implementación de su práctica. Esta idea (la continuidad de las prácticas humanas, la acumulación de las mismas) está relacionada con un concepto y un par de casos ilustrativos que quiero discutir antes de pasar a la reconstrucción de itinerarios y alteraciones del paisaje que nos ocupa. Me refiero a la acumulación de conocimiento en relación con los usos del espacio que ha sido llamada, por algún investigador, "capital paisajístico" (Erickson, "The Social Organization" 381) o "memoria del paisaje". Uno de los casos que ilustra esa acumulación tiene que ver con la relación entre los indígenas del tiempo histórico y la sociedad criolla independentista que llevó adelante el proyecto del estado/nación moderno en la franja de tierra al norte del Plata. Me refiero a la influencia que, según Carlos Maggi, tuvo el conocimiento topográfico de los charrúas en la carrera política y militar de José Artigas. Según el citado autor, la evidencia documental sugiere que el baqueano Artigas había aprendido a transitar el territorio al norte del Río de la Plata gracias a su contacto con los indios charrúas (58). Algunas victorias importantes (casi las únicas de su carrera, signada por el fracaso y la traición de sus aliados y allegados) habrían estado basadas en una práctica del espacio posibilitada, en gran parte, por el conocimiento indígena de los accidentes del terreno (Maggi 134s). Huelga, en este caso, destacar la importancia que habría tenido, para el desarrollo posterior de la vida social en ese territorio, el aporte de los charrúas en materia de prácticas y conocimiento del espacio.

El otro caso ilustrativo que quiero comentar es el de la práctica prehistórica de un territorio andino (en lo que hoy es Bolivia) que está teniendo consecuencias importantísimas para sus habitantes actuales. Se trata del proyecto de arqueología experimental que está llevando a cabo Clark Erickson en varios puntos de las zonas bajas e inundables de Bolivia (ver su "Prehistoric Landscape" para una descripción del mismo). Allí se están reconstruyendo ciertas prácticas de explotación de la tierra (abandonadas en el tiempo histórico) que consisten en levantar artificialmente la altura de las mismas, mediante la acumulación de tierra y despojos, a fin de protegerlas contra las inundaciones. Esta tarea 
de ingeniería va acompañada de una red hidráulica de canales que comunican las diferentes parcelas elevadas artificialmente. Las ventajas de este tipo de obra han sido comprobadas por los resultados obtenidos: se evita la anegación y se facilita la irrigación para la estación de sequías. El trabajo que insume este tipo de operaciones es mucho al tiempo de su construcción, pero su mantenimiento posterior es sumamente económico, exigiendo muy pocas horas de trabajo. Permite, además, que un pequeño grupo social e incluso un núcleo familiar, mantengan la elevación y los canales funcionando. Las cosechas obtenidas hasta ahora son sumamente satisfactorias si se las compara con otros medios de explotación de la tierra que se están usando contemporáneamente en zonas de idénticas características, lo cual quiere decir que ese "capital paisajístico prehistórico" puede ser recuperado y usado, con beneficio, en el presente (datos que figuran en "The Social Organization"). ${ }^{\text {' }}$

En el caso de la ribera norte del Río de la Plata, la tarea de reconstrucción de prácticas sobre el espacio es sumamente difícil por varias razones. Ante todo, la magra (por reciente) tradición arqueológica que tiene como objeto de estudio el territorio en cuestión (Cabrera, "Panorama" 23). En esa breve historia disciplinaria, sin embargo, varios marcos teóricos han sido ensayados. Todos ellos comparten, a pesar de sus diferencias, una visión que implica, de una manera u otra, una perspectiva evolucionista de la prehistoria basada en el difusionismo(LópezMazzy Bracco, "Las sociedades prehistóricas" 108). Es decir, todas las corrientes arqueológicas en el Uruguay han postulado, implícitamente, una escala jerárquica para las civilizaciones, que consiste en poner a la cultura europea al tope de la misma y en juzgar (y clasificar) a las culturas aborígenes estudiadas según se acerquen más o menos al patrón establecido por la cultura "superior" y sus tecno-complejos (López Mazz y Bracco, "Las sociedades prehistóricas" 109). Desde las antípodas de este marco teórico es que voy a ocuparme de los seres humanos que poblaron el territorio en cuestión antes del tiempo histórico.

Una de las inscripciones indígenas más notorias y misteriosas para el observador moderno es el llamado arte rupestre: fundamentalmente los petroglifos (piedras grabadas) y las pictografías (rocas pintadas). Lamentablemente, el nombre mismo que les asignamos en tanto que serie de objetos estudiable (arte rupestre), deja bastante que desear y puede llevar a confusión, al mismo tiempo que deja al desnudo algunas de las limitaciones cognitivas que el observador trae consigo al abordar el estudio de esos objetos. Como bien señala Consens, esta designación es sumamente inadecuada porque presupone que las sociedades productoras de petroglifos y pictografías tenían una actividad equiparable a la que en la cultura occidental conocemos como arte ("Arte rupestre en el Uruguay" 62). Por

\footnotetext{
' Otro ejemplo que podría invocarse es el que ofrece Taussig en su estudio sobre los indian carriers de Colombia durante el siglo XIX, que cargaban a sus espaldas a los españoles cuando necesitaban viajar por zonas inhóspitas (287-335). Se trataba del tránsito de caminos que ya existían cuando llegó el conquistador, los cuales ponían en comunicación las redes de comercio entre los distintos grupos hasta la llegada de los españoles (296), momento en el que ese tipo de comunicación entre los aborígenes se abandonó, como ocurrió con la mayoría de las instituciones y prácticas indígenas que se intentaron sustituir por otras de origen europeo. El reciclaje decimonónico de esas rutas abandonadas es un caso más que ilustra esa acumulación de prácticas y conocimientos sobre el paisaje de que estoy hablando.
} 
otro lado, es evidente que estos dibujos sobre piedra no pretendían ser comprendidos fuera del grupo que los creó y que son sólo la parte material de un complejo sistema de comunicación (Consens, "Arte rupestre y mobiliar" 18-19). De modo que el primer paso al abordar el estudio de estos objetos debe ser el reconocimiento de los diferentes parámetros culturales que separan a las sociedades estudiadas de la nuestra (Castellano y Consens 134).

Teniendo este caveat siempre en mente, digamos que hasta hace muy poco se creía que la mayoría de las inscripciones rupestres en el territorio estudiado (que de aquí en adelante llamaré uruguayo, por comodidad y a sabiendas de su inadecuación histórica) estaba integrada por pictografías ( 15 yacimientos conteniendo unas 40 o 50 pictografias, según Peláez Castello 67). A partir de un reciente hallazgo (unos 210 petroglifos en un radio de 10 kilómetros), se puede decir que el panorama general ha variado sustancialmente, pasando a ser este tipo de trabajo en roca el predominante en lo numérico (Curbelo 1321). ${ }^{2}$ Este hallazgo no sólo es de fundamental importancia para la prehistoria del territorio que estamos estudiando, sino también para el continente sudamericano en su totalidad, especialmente en lo que se refiere a las presunciones más aceptadas sobre la producción de petroglifos: que deben de haber sido elaborados por muy poca gente o por escasos grupos sociales, ya que de lo contrario habría hoy un mayor número de piedras grabadas para estudiar (Dubelaar 82). Con esta aparición masiva de objetos, parecería razonable revisar la antedicha presunción o, por lo menos, los criterios a través de los cuales se llegó a ella (relación entre población y cantidad de objetos arqueológicos hallados).

De las culturas que produjeron estos objetos, poco sabemos. Una de las carencias fundamentales que existe hoy en el área de estudios es la ausencia de dataciones absolutas, por lo cual debe recurrirse a diversos métodos de fechado indirecto (Dubelaar 34). ${ }^{3}$ Uno de los más confiables es el estudio del entorno, por ejemplo, la cerámica asociada al sitio (Dubelaar 40), pero no siempre se tiene la suerte de encontrarla (como se desprende de la investigación que describe Consens, "Evaluación de un sitio" 173). La misma dificultad

\footnotetext{
${ }^{2}$ El lugar del hallazgo no se conoce con precisión (aunque sí se sabe que está situado en el departamento de Salto), debido a las medidas de seguridad y secreto que las autoridades han tomado, a fin de proteger estas reliquias de la curiosidad y potencial vandalismo de un público lego (Curbelo 20). Ya sea voluntaria (explotación del yacimiento como cantera industrial, transformando la reliquia en adoquín, etc.) o involuntariamente (graffitis, orines, etc.), el ser humano es el depredador de arte rupestre más temido por los arqueólogos, como bien explica Consens (citado en Barrios Pintos, Los aborigenes 21-23), afirmación que repite en "Arte rupestre en el Uruguay" (62). ${ }^{3}$ Los arqueólogos han intentado varias aproximaciones al problema del fechado, llevando a cabo estudios de la pátina que cubre la roca, análisis por activación de neutrones, estudio de líquenes (en las zonas en que estos rodean al objeto de estudio), de erosión, etc. (Dubelar 35-39). Pero por ahora lo más seguro es analizar el material asociado fechable, es decir, los datos arqueológicos que componen el contexto en el cual se erige la piedra grabada o pintada. Estos son los que permiten relacionar el objeto con los horizontes culturales que lo rodean (Dubelar 40). Existen algunos fechados indirectos de pictografías en el territorio uruguayo (obtenidos a través del estudio de pátina, del material lítico asociado y de las alteraciones químicas en la superficie), como puede verse en la investigación de Consens (“Arte rupestre y mobiliar" 22), donde se establece un primer período de ejecución alrededor del $6000 \mathrm{AP}$ (antes del presente) y un segundo, aproximadamente, entre el 4000-2000 AP.
} 
existe para la datación a través de Carbono 14, para la cual es necesario hallar relictos de combustión, así como también para el fechado por restos alimenticios (nuevamente, tomemos como ejemplo la investigación citada en Consens, "Evaluación de un sitio" 173).

Es claro que sin fechas absolutas es sumamente difícil atribuir estas prácticas rupestres a un grupo o etnia específicos, que permitan al investigador determinar, con mayor fundamento, la posible función de aquéllas. A pesar de esta seria limitación, hay algo en lo que todos los estudiosos coinciden: estas manifestaciones rupestres tienen sentido (Dubelaar 49). Lo difícil es establecer, sin la ayuda del contexto cultural, qué sentido tienen. En el caso del territorio uruguayo, no hay ni siquiera una cultura indígena histórica sobreviviente. Si bien es cierto que los aborígenes del tiempo histórico han demostrado consistentemente ser de escasísima ayuda para el investigador (Dubelaar 57), ${ }^{4}$ su testimonio sería relevante para una investigación como la presente, que intenta señalar cierta memoria del paisaje, a través de las sucesivas apropiaciones del territorio por parte de diversas culturas. No interesaría, entonces, que los indígenas mintieran o inventaran historias totalmente ajenas a las intenciones y fines de los productores de las piedras inscriptas, ya que esa actitud sería, en sí misma, un reciclaje de prácticas previas sobre el espacio, una reinterpretación de ciertas inscripciones sobre el territorio.

El caso es que los arqueólogos han intentado especular sobre este asunto, dando una serie de explicaciones sobre la posible función y sentido de los petroglifos. Algunos los han relacionado con prácticas mágicas y religiosas, otros los conciben como perpetuadores de memoria (de hechos o sucesos memorables), como tótems, como objetos con sentido calendárico, como reproducciones de ciertas figuras producidas por los fosfenos causados por algunos alucinógenos (Dubelaar 75-78). Lo único que es seguro es que se trata del relicto de una serie de actividades que no se hallan vinculadas directamente a actividades de subsistencia (Consens, "Arte rupestre en el Uruguay" 62). A partir de este presupuesto, la interpretación más interesante para la presente investigación es la que los vincula con prácticas demarcatorias del territorio o como signos orientadores (ídem 78). De ser ésto cierto, estaríamos ante una práctica humana claramente orientada a operar sobre el territorio. Pero el apresurarse a abrazar una hipótesis sólo porque confirma el presupuesto de la investigación en curso es, cuando menos, un movimiento teórico discutible. Por lo que sabemos de las sociedades no occidentales que poblaban el territorio americano antes de la llegada del visitante europeo, el conocimiento corográfico que poseían de su hábitat era lo suficientemente adecuado como para hacer innecesario ese tipo de señalización (argumento que comparte Dubelaar 79). El mojón señalizador, tan necesario para las prácticas espaciales occidentales, parece una redundancia innecesaria en una cultura que probablemente conocía al dedillo los detalles topográficos de su territorio. Los estudios sobre el conocimiento territorial de algunos aborígenes históricos tienden a concluir que se trataba, en general, de gente que no necesitaba de una brújula para orientarse, como bien

\footnotetext{
${ }^{4}$ En el caso de los petroglifos, se han hecho encuestas con los indios históricos y los resultados han sido desalentadores. Se supone, en general, que los mitos que los nativos relacionan con las piedras grabadas son explicaciones ex post facto, cuya finalidad es dotar de sentido al artefacto (Dubelaar 69).
} 
señala Boelhower (53). Sin embargo, uno de los usos posibles de los petroglifos relacionados con el espacio es el de demarcación del territorio propio; es decir, el petroglifo (o la pictografía) usados como demarcación de frontera. Esto no es fácil de demostrar, debido a que no sabemos con certeza si los pueblos que produjeron las inscripciones eran sedentarios, nómades o semi-nómades (ya veremos que el estudio de la evidencia arqueológica es incipiente a este respecto, para cualquier época de la prehistoria del territorio), lo cual deja abierta la incógnita sobre el valor que los productores le asignaban al sitio, con qué frecuencia lo visitaban, qué actividades desarrollaban allí, etc. De modo que es muy aventurado suponer que tuvieran un concepto de frontera o (más aventurado aún) de derecho de propiedad territorial comunitaria (opuesta a la de otros grupos vecinos), sobre todo porque no sabemos, como ya se ha dicho, qué tipo de ocupación del territorio acostumbraban.

Una hipótesis más seductora es la que postula a las piedras inscriptas como señales de lugares importantes para la comunidad. En este último caso, la relación del sitio con prácticas culturales tales como la magia o el ritual, es más que razonable (ya veremos más adelante que algunos etudiosos han planteado este tipo de relación entre sitio y actividad cultural en el caso de los cerritos o mounds). Se trataría entonces (en esta hipótesis) de lugares específicos cuyo carácter privilegiado se indicaría por medio del objeto lítico.

Sea como fuere, no parece exagerado vincular al objeto rupestre y el lugar en que se ubica, porque como bien señala Dubelaar, lo único que es razonable suponer con cierto grado de certeza es la especial relación entre la roca inscripta y su ubicación (83). Esto se deduce de muchos casos en los que es claro que la materia prima (la roca) no ha sido trasladada desde otros contextos, sino que se ha aprovechado la que se encontraba en el sitio (Dubelaar 83). Pero también se puede conjeturar esta especial relación a partir de la ubicación de los petroglifos con respecto a los accidentes del terreno. Por ejemplo, la mayoría de ellos se da cerca de (o en) los ríos o cursos de agua, a tal punto que a veces dificultan la navegación (Dubelaar 27). Su relación con el agua se hace más fuerte todavía si tenemos en cuenta que en algunas ocasiones es posible encontrarlos en las inmediaciones costeras (Dubelaar 28).

Teniendo en cuenta todo lo dicho anteriormente, y tratando de superar la falta de certezas en cuanto a fecha, función, sentido y atribución de autoría, cabe recordar que a pesar de todo, esas marcas en el territorio están allí, como testimonio de pueblos que operaron sobre ese espacio. Y no lo están sólo para nosotros, los observadores del siglo veinte, sino que también estuvieron allí para los indígenas del tiempo histórico. Uno de los objetivos de la investigación de estas rocas inscriptas debería ser, según la orientación del presente trabajo, una pesquisa que intente desenterrar, en la medida de lo posible, los usos a los que los aborígenes del tiempo histórico podrían haber sometido a las piedras inscriptas (sobre los usos depredadores a que los sometemos los habitantes del siglo veinte, ya sabemos demasiado). Sería posible, así, establecer una cierta continuidad (o acaso percibir rupturas) entre los sucesivos usos del mismo espacio territorial, una especie de acumulación de conocimiento sobre los usos del suelo que se ha dado en llamar capital paisajístico.

Sobre las pictografias y petroglifos se sabe y se ha investigado relativamente poco, pero existen otras marcas y modificaciones prehistóricas del paisaje que han recibido 
mayor atención y cuya abundancia facilitará la futura tarea de producir conocimiento sobre ellas: los llamados cerritos de indios o mounds. Por tratarse de una práctica arquitectónica fácilmente visible (elevaciones de hasta 4 metros), ha llamado la atención de los estudiosos y aficionados desde muy temprano, casi desde la "prehistoria" de los estudios arqueológicos en el Uruguay moderno. ${ }^{5}$ Es en los últimos años, sin embargo, que los avances más significativos se han producido en esa área de estudios. A partir de las excavaciones de un numeroso grupo de investigadores, el territorio ubicado en la región más oriental del territorio uruguayo está rindiendo altos dividendos para el saber arqueológico. ${ }^{6}$ Lo que se ha dado en llamar Proyecto de rescate arqueológico de la cuenca de la Laguna Merín (PRALM) abarca la franja de tierra delimitada por la citada laguna, el Océano Atlántico, el Río Cebollatí y las serranías del Este (Bracco, "Desarrollo cultural" 3). El clima de la región es subtropical húmedo y predominan las planicies medias, bajas y esteros y bañados (ídem 3). Así descripta y delimitada, ésta es la región considerada (por dos de los principales investigadores a cargo del PRALM) como una unidad de análisis arqueológico (Bracco y López Mazz, "Relación hombre-medio ambiente" 261). Si bien esta unidad es compleja y contiene sitios de diversa índole, son los cerritos los que han recibido la mayor atención tanto de arqueólogos como de público en general. ${ }^{7}$ Se trata de elevaciones producidas artificialmente por el ser humano en lugares específicos del territorio, lo cual indica, de parte de los constructores, una estrategia deliberada de ocupación (Ferrés 140; López Mazz y Bracco, "Cazadores colectores" 5). En este trabajo voy a considerar brevemente algunas de las otras concentraciones de material arqueológico, pero en general seguiré la tendencia mayoritaria y me concentraré en las implicaciones del uso del espacio en forma de cerrito. Siempre, sin embargo, teniendo en cuenta la definición de sitio arqueológico propuesta por Bracco y López Mazz: aquel que comprende tanto al cerrito como a sus áreas circundantes, sin limitarse exclusivamente a la estructura monticular ("Relación hombre-medio ambiente" 268). En este sentido, coinciden con los presupuestos metodológicos que indican que no se debe separar el sitio de sus alrededores, sino que debe entenderse a ambos como parte de un continuum (Borrero y Lanata 150). De modo que aunque el centro de atención sea el sitio con elevación, será necesario recurrir a la información del contexto arqueológico para entender mejor su estructura y funciones. De ahí que los estudios del PRALM, en algunos casos, se extiendan a tierras comprendidas en un radio de veinte kilómetros con respecto al sitio, que constituyen la zona de potencial abastecimiento del grupo humano (Curbelo et al. 338).

\footnotetext{
${ }^{5}$ Para una sumaria revisión de la historia de los estudios sobre cerritos en el Uruguay, pueden verse, entre otros, los siguientes artículos: Bracco, "Desarrollo cultural" (2); Bracco y López Mazz, "Cazadores colectores" (4-6).

${ }^{6}$ Además de haber interesado, por primera vez, a vastos públicos no especializados. Así lo sugiere la importante cobertura periodística que las excavaciones comenzaron a tener en el año 1996, llegándose incluso a dedicarles un programa especial en la televisión.

${ }^{7}$ Estas estructuras, también llamadas mounds, son numerosísimos en la zona, habiéndose constatado la existencia de más de ochocientos de ellos según el informe de Bracco y López Mazz ("Rescate arqueológico") y más de seiscientos según otra fuente del PRALM (Curbelo et al 333).
} 
La ocupación del área estudiada debe de haber ocurrido, según los investigadores, en una fecha cercana a los $2500 \mathrm{AP}$, fecha en que se produjo, según los estudios geológicos, un dramático cambio en el clima de la región. La hipótesis que se maneja es que el comienzo del poblamiento de la región tiene lugar, precisamente, después de ese cambio ambiental, en tanto que la ocupación de las serranías vecinas se produjo unos mil años antes (López Mazz, "Aproximación al territorio" 69). Este es un dato relevante si se cree que el uso del espacio por parte de grupos humanos puede estudiarse en tanto que parte del sistema de subsistencia o, en otras palabras, como territorio de explotación (Pérez de Micou, Bellelli y Aschero 55); es decir, un estudio que tenga especialmente en cuenta (como ocurre en numerosos estudios del PRALM) la relación que se da entre medio ambiente y ser humano o, en terminología usada por Bracco, entre asentamiento y sistemas de producción de alimentos ("Desarrollo cultural" 9). Estos revelan que los recursos que el paisaje ponía a disposición de aquellos pobladores que llegaron hace unos 2500 años a la región estudiada, eran más abundantes de lo que se creía antes de la serie de investigaciones que comenzó en el año 1986. El análisis de los restos de fauna encontrados revela la abundancia de mamíferos de gran porta, en especial un tipo de cérvido ya desaparecido, proveedor masivo de carne (Bracco y López Mazz, "Relación hombremedio ambiente" 274). El pecarí, hoy extinguido, también proliferaba por los palmares rochenses y zonas aledañas a la Laguna Merín, igual que algunos anfibios, como carpinchos y nutrias, de gran valor económico incluso en el presente (ídem 274). Para dar una idea de la riqueza faunística de la región, baste recordar que en el presente, el $30 \%$ de las especies de animales que existen en el territorio del Uruguay, se concentran en la región bajo estudio (Lagomarsino et al. 3). Los lobos marinos también fueron un recurso de importancia, por su porta, concentración y fácil captura (Bracco y López Mazz, "Relación hombre-medio ambiente" 275).

Pero lo que tal vez distinga a estos sitios de otros del territorio es la abundancia de palmares (que todavía puede observarse) de butiá (Butiá capitata), los cuales cubren actualmente unas 200.000 hectáreas, pero se presume que por los tiempos en que el cambio climático y la ocupación ocurrieron, su área pudo haber sido todavía mayor (idem 275). Este elemento ha sido fundamental para las investigaciones del PRALM, que lograron extraer conclusiones de suma utilidad para comprender la economía de explotación de la región hace unos dos mil quinientos años. Debido a que se ha encontrado consistente evidencia del consumo de butiá (semillas quemadas y quebradas fueron halladas en varios de los sitios excavados, además de un artefacto llamado "rompe-coco"), el panorama arqueológico de la región ha cambiado sustancialmente según los estudiosos. Por empezar, el modelo que se propone ahora es el de cazadores-colectores que habitaban y explotaban un territorio de alta productividad, debido a los valores de retorno (diferencia entre inversión y beneficio) que se presume tenían los recursos disponibles (ídem 276). Esta caracterización se basa en que, en la literatura especializada, las dos especies de mayor retorno son habitualmente los cérvidos y las nueces, ambas encontrables en abundancia en la región excavada (ídem 276).

Esta pintura de la situación económica derivada de la explotación del territorio, junto con el alto número de estructuras monticulares halladas, permite aventurar la hipótesis de una alta concentración poblacional, cosa que contradice las ideas que predominaban antes 
de las recientes investigaciones (ídem 277). Lo cual armoniza con las conclusiones a que puede llegarse luego de estudiar la relación entre cerritos (estructuras que requieren una inversión de tiempo y energía considerables) y recursos naturales abundantes, llegándose a sugerir el siguiente panorama: "altas concentraciones de población, con estrategias económicas de eficiencia tal que tolerarían una inversión de energía tan alta [construcción de las estructuras monticulares] sin retorno utilitario" (ídem 277). La alta eficiencia de que se habla tiene que ver con la gran productividad (al menos potencial) del medio ambiente.

Se le atribuye a estos cazadores- (cuyas actividades predatorias incluían la caza de cérvidos, nutrias, etc.) colectores (de butiás y moluscos, fundamentalmente) una "explotación del ciclo anual de diferentes ambientes aprovechados estacional, continua o esporádicamente" (ídem 277). ${ }^{8}$ Esta presunción de que existía un ciclo anual de explotación (y por lo tanto de ocupación), conduce, junto con otras evidencias, a la conclusión de que estos grupos exhibían un cierto grado de sedentarismo, lo cual agrega todavía una discrepancia más con la pintura tradicional de los grupos cazadores-colectores en la literatura especializada en general y en la dedicada al territorio uruguayo en particular (que los presenta como grupos nómades poco numerosos debatiéndose contra los escasos recursos del medio ambiente, como explica López Mazz en "Las sociedades prehistóricas" 111). López Mazz y Bracco afirman que las evidencias que sugieren cierto grado de sedentarismo entre los grupos pobladores son el tiempo que insume la construcción de cerritos, sumado a las bondades en materia de posibilidades para la subsistencia ofrecidas por la región (ídem 278). Pero hay todavía otro elemento que apunta en esa dirección y que convendría analizar más en detalle: la posible función (o funciones, como ya veremos) que los cerritos cumplían en la sociedad que los produjo.

Es evidente la dificultad de elucidar, hoy, el uso a que estas estructuras eran destinadas. Los parámetros culturales en que estamos insertos son más una barrera que un puente en ese sentido. Sin embargo, la arqueología ha desarrollado una serie de métodos de pesquisa y deducción que permiten un cierto grado de racionalidad a las hipótesis que se elaboran. Por ejemplo, resulta evidente que si se encuentran restos óseos humanos en determinadas posiciones, estamos ante un sitio cuyas funciones incluían, cuando menos, la de enterradero o lugar funerario. En el caso de algunos cerritos estudiados por el PRALM, se han encontrado esos tipos de restos. Todos ellos se hallan, sin excepción, en la parte central de la estructura y a diferentes profundidades (Femenías et al. 348). Se trata de veinte enterramientos individuales, dos enterramientos conjuntos $y$ diecisiete indeterminados (ídem 348). La forma en que se encuentran enterrados permite dividirlos entre primarios (la mayoría de ellos, 15) flexionados, tres secundarios (es decir,

${ }^{8}$ La explotación estacional presupone que se establecían en distintas regiones según las épocas del año; en el caso de los cerritos, la evidencia apunta a una ocupación del período primavera-verano (López Mazz, "El fósil que no guía" 94). La explotación de recursos en el marco de una misma estación no sólo se daba en el sitio arqueológico propiamente dicho, sino tambíen en las zonas aledañas ubicadas más allá de la zona de $20 \mathrm{~km}$ propuesta como límite tentativo de aquél: colmillos de lobo marino hallados a $30 \mathrm{~km}$ de la costa sugieren una explotación vinculada de zona costera y zona baja inundable (López Mazz y Bracco, "Relación hombre-medio ambiente" 275). 
que no se han enterrado allí inmediatamente después de la muerte del individuo) en "paquete", dos secundarios en urna, ocho indeterminados y doce sin información al respecto (idem 348).

Durante el estudio de estos casos, surgió clara la co-presencia de testimonios de combustión, que sugiere una recurrencia entre ambos elementos (ídem 351). Lo interesante del caso es que las estructuras de combustión no presentan las características típicas de uso para habitación o uso culinario, sino que parecen pasibles de ser clasificadas como de tipo ceremonial (López Mazz, "Aproximación a la génesis” 90). Los agujeros o improntas ocasionadas por pequeñas ramas parecen no ser, tampoco, vestigios de habitación sino residuos de alguna actividad ritual vinculada a la funebria (ídem 90). Estas actividades (la funeraria junto con la ceremonial) son las que dan continuidad a la evolución de los cerritos, ya que aparecen en diferentes momentos de su evolución (ídem 93). Las sociedades que esos restos funerarios sugieren es de tipo complejo, con una organización del trabajo comunitario bastante sofisticada, a juzgar por el tratamiento dado a los muertos (López Mazz, "Las sociedades prehistóricas" 111) que consiste en un trato diferencial a los diferentes individuos enterrados, lo cual permite conjeturar el incipiente surgimiento de una sociedad no igualitaria (López Mazz, "Aproximación al territorio" 71). ${ }^{\prime}$

Creo que lo dicho sobre los cerritos da una idea aproximada de lo que se sabe o deduce sobre la cultura que los construyó. Lo que no está claro todavía (ni siquiera para los estudiosos a cargo de los proyectos de investigación) es qué otras funciones pueden haber tenido además de la funeraria y la ceremonial. Sí se puede afirmar, sin embargo, que existe una estrecha relación entre algunos elementos del paisaje y la estructura monticular (Bracco, "Desarrollo cultural" 1) y que la distribución de esos túmulos en el espacio no sólo no es aleatoria sino que "acompaña y reafirma los accidentes [topográficos] que estructuran la región" (López Mazz. "Trabajos en tierra" 2)." Una de las hipótesis más comunes (entre las que tienen en cuenta la relación de las estructuras antrópicas con el territorio) y por ahora más compartidas entre los investigadores, está relacionada con aquella que habíamos visto propuesta para los petroglifos: me refiero a la que los caracterizaría como marcas territoriales. A este respecto, se han esbozado distintas interpretaciones, ninguna de las cuales ha recibido confirmación suficiente a través de datos arqueológicos definitivos. En uno de los primeros trabajos del período de investigación que comienza en 1986, se sugiere que los cerritos podrían haber funcionado como elementos de cohesión social, permitiendo al grupo marcar su identidad o la de su territorio (Femenías et al. 352). Este tipo de señalamiento sería reflejo de integración, cooperación y creencias comunes, además de la demarcación territorial (propio de

? En un trabajo anterior del PRALM, se había aventurado la hipótesis contraria (sociedad igualitaria), cuyo fundamento fue el ajuar asociado (litos pulidos, huesos, colmillos, collares de conchas, etc.) a los muertos en los enterramientos estudiados (Femenías et al. 352). Según Tainter, el tratamiento a los muertos en forma diferencial es, precisamente, un marca que indica jerarquías en la estratificación social (107). El ritual, según este mismo autor, en tanto que sistema de comunicación, revela información sobre el status del muerto (113).

10 Según Bracco, siguen en general los cursos de agua, ubicándose en el nivel inmediato superior al de la llanura de inundación ("Desarrollo cultural" 8). 
sistemas de cacicazgo), según López Mazz (“Trabajos en tierra” 4), lo cual se corresponde con los modelos explicativos más aceptados sobre las sociedades complejas y la función del monumentalismo (megalitos, túmulos, cerritos, etc.) en ellas: contribuir a organizar y a especializar las prácticas religiosas asociadas a la concentración creciente de un poder político (ídem 4).

Volviendo a la función demarcatoria de los cerritos, digamos que recientemente López Mazz ha desarrollado esa hipótesis en otra dirección. La idea ahora es que la estratégica implantación territorial de las estructuras monticulares podría estar vinculada a vías de comunicación y zonas de concentración de recursos, sugiriendo así su posible pertenencia a redes de intercambio entre los grupos que se movían en el paisaje estudiado (López Mazz, "Trabajos en tierra" 4). Algunas de las ilustraciones (por no llamarlas mapas) de la ordenación de diversos grupos de mounds en el espacio ofrecidas por el autor, pueden inducir a pensar que, efectivamente, la organización del espacio entre los mismos pudiera responder a ciertos diseños deliberados (ídem 9). Por supuesto que sólo se trata de una hipótesis que requiere confirmación a través de datos más definitivos que el mero orden percibido por el observador moderno, quien puede estar imponiendo al objeto estudiado características que no le son, necesariamente, intrínsecas, sino que pueden pertenecer al contexto de descripción (o episteme) desde el que se posiciona el investigador. ${ }^{11}$

Todo lo que sabemos sobre arte rupestre y cerritos apunta claramente a una conclusión: los habitantes prehistóricos del territorio al norte del Río de la Plata dejaron sus inscripciones en el mismo. Desde los petroglifos (posibles marcas de lugar sagrado o de posesión y/o delimitación del territorio) a las elevaciones de origen antrópico, las marcas han quedado. Es decir que las actividades que les dieron origen forman parte de la historia de las prácticas humanas posteriormente desarrolladas en esa misma parte del territorio, haciendo posible la pervivencia, allí, de esas señales que formarán el acervo o capital paisajístico heredado por los grupos que vendrían después. Los indígenas del tiempo histórico no dejaron de percibirlas, como sugiere la abundante documentación sobre los "bichaderos" (o "vichaderos": pirámides de piedra edificadas sobre elevaciones o cerros), que servían de túmulo a los charrúas (Pi Hugarte 117-118). ${ }^{12}$ Incluso puede llegar a suponerse, según algunas fuentes documentales, que para alguna parcialidad de los charrúas esos lugares con elevación podían tener alguna relación con actividades mágicas o religiosas (si es que tenían alguna), como en el caso del cerro Bichadero, adonde concurrían los supuestos hechiceros "guenoas" (Barrios Pintos, "Los indígenas" 27-28; Cavellini 111). ${ }^{13}$ De lo que no cabe duda es de la utilización de los cerritos por parte de

\footnotetext{
"Para una discusión de la relación entre el objeto estudiado y el contexto de descripción en el que se mueve el investigador, puede verse el trabajo de Maturana y Varela (67-69).

${ }^{12}$ El uso de elevaciones para funciones fúnebres por parte de indígenas del tiempo histórico puede ser una mera coincidencia, pero también puede deberse a prácticas del espacio aculturadas o imitativas. Sobre los "bichaderos" poco se sabe con certeza, aparte del uso que la documentación atribuye a los charrúas (por ejemplo, no se sabe si las pirámides fueron construídas por ellos mismos o por otra etnia). Para tener una idea de los "bichaderos" localizados y una descripción somera de los mismos, puede verse el artículo de Femenías.

13 Este asunto de las parcialidades charrúas no está demasiado claro para mí (ni para nadie), pero uso la denominación "guenoas" (a pesar de que no se sabe demasiado bien si eran una parcialidad
} 
los habitantes rurales del Uruguay moderno, quienes se amparaban en las elevaciones artificiales para escapar a las inundaciones, prolongando de esta manera la vida útil de las construcciones prehistóricas, como surge de un artículo (1927) de Ferrés: "Hubo años en que los vecinos mismos hallaron refugio en esos antiguos cementerios, transformándolos en verdaderas viviendas" (citado en Vidart, "Los cerritos" 54-55); "si tenéis que destacar en aquellos campos a una peonada para un trabajo de alguna duración, la peonada elegirá, para acampar, los mismos lugares de la costa del estero donde otrora levantaron los indios sus plataformas" (ibídem 60).

Otro caso que parece apuntar a una utilización del mismo espacio por culturas separadas en el tiempo es el de las cuevas de la zona de San Miguel (Departamento de Rocha), en las cuales se han encontrado (junto a los desechos líticos) restos óseos vacunos que no pueden tener una antigüedad que vaya más allá del siglo XVII, época en que se introdujo este tipo de ganado en el territorio (Beovide 55).

Esta continuidad en los usos del territorio no se da simplemente entre una cultura anterior y la que la procede, sino que sabemos que se dio (de manera más directa y contigua), también, dentro del devenir histórico de la cultura que construyó los cerritos. López Mazz habla, precisamente, de la estructura palimpséstica de los sitios estudiados, que indica las sucesivas ocupaciones del mismo lugar a través del tiempo y cuya manifestación más evidente se encuentra en las diversas remodelaciones de las estructuras monticulares ("Trabajos en tierra" 10). ${ }^{14}$ Dicho de otro modo: dentro de la propia cultura que construyó los cerritos se dieron distintos usos (durante las sucesivas ocupaciones) de la estructura monticular heredada. ${ }^{15}$

Lo interesante de esta cultura constructora de cerritos es que no solamente precedió a las etnias históricas del territorio, sino que llegó a coexistir con ellas e, incluso, con la llegada de los invasores europeos, como indican los quince fechados de carbono 14 (correspondientes, en algunos casos, a elementos individuales dentro de los sitios, como carozos de butiá y tallos de palma) que apuntan a fechas bien entradas en el tiempo histórico (Bracco, "Desarrollo cultural" 12). A pesar de la confiabilidad general de este tipo de datado, Bracco advierte sobre los inconvenientes que plantean algunas muestras (especialmente los desechos), por no saberse, entre otras cosas, el tiempo que transcurrió desde su producción como desecho hasta su integración a la estructura del cerrito

diferente o si estamos meramente ante un problema de denominación) porque se trata de un grupo indígena del tiempo histórico abundantemente mencionado. Para una breve (contradictoria e inconsistente por momentos, pero también ilustrativa) discusión de la identidad y denominación de esta hipotética parcialidad, ver Vidart 19.

Las prácticas mágicas de tipo chamánico de charrúas o guenoas son, también, objeto de discusión y causa de incertidumbre, como puede verse en Pi Hugarte 122.

${ }_{14}$ Las dichas remodelaciones se demuestran por varias vías: geomorfológicamente, por la asociación de las ocupaciones a paleosuperficies de diferente edad; por la significativa densidad o agregación de material arqueológico en las olladas interdunares; y por la abundancia de materiales con trazas de reciclado (López Mazz, "El fósil que no guía" 95).

is Una estructura que, por otra parte, parece prever desde su propia génesis la potencial transformación de sí misma (López Mazz, “Aproximación a la génesis” 91). 
(“Dataciones 14C"14). ${ }^{16}$ La datación que propone la fecha 370 AP (aproximadamente) como la de la ocupación más tardía, aunque es de baja resolución, tiene la ventaja de que su desviación es limitada, precisamente, por ser tan tardía (ídem 14). Esa fecha que señala lo dicho anteriormente (que los constructores de cerritos coexistieron con las etnias históricas conocidas y con los europeos) se ve apoyada por evidencia adicional: la presencia de material atribuíble a la cultura europea en los niveles superiores del sitio CH1E01 (ídem 15). ${ }^{17}$ La pregunta que surge ante esta evidencia es la siguiente: ¿por qué si sobre charrúas, chanáes e incluso algunas etnias inexistentes (como los arachanes), es posible encontrar referencias en las crónicas de los siglos XVI y XVII, no se conoce alusión etnográfica alguna sobre la que construyó los cerritos? La otra interrogante que se plantea tiene que ver con su súbita desaparición ${ }^{18}$ (al menos con respecto al lugar habitado, al sitio arqueológico), según lo indicado por los más recientes estudios. Según Bracco, la respuesta a la segunda pregunta puede provenir de los dramáticos cambios producidos por la presencia de la cultura europea en la región, sin que esto sea adherir a una causalidad simplista entre contacto y desaparición (ídem 15; Cabrera, "El indígena y la conquista" 116). La interacción con el recién llegado y su cultura (la cual comprende tecnologías, utensilios, prácticas sociales y del espacio), entonces, puede haber tenido algo que ver con la súbita desaparición de la misteriosa (para nosotros) etnia estudiada. De ser esto así, es evidente que para el visitante europeo la zona de la Laguna Merín no era (no podía ser) una página en blanco, porque allí estaban los cerritos y sus constructores para atestiguar lo contrario. $\mathrm{O}$, simplemente, los cerritos abandonados, porque los primeros contactos entre esos dos mundos tan diferentes se dieron, en muchas ocasiones, de manera indirecta: a través de sus objetos (montículos, utensilios-tanto aborígenes como europeos-, etc.) y animales (ya sea los que los visitantes traían o los que explotaban los aborígenes), antes que por el contacto directo entre los moradores y "los recién llegados" propiamente dichos (ídem 15). Es precisamente esta hipótesis, la que postula el contacto indirecto de las culturas de la región con el visitante europeo, la que podría explicar la ausencia de referencias a aquéllas en los textos de los conquistadores. De este modo, puede suponerse que la falta de alusiones a los habitantes de los palmares del Este se deba a que éstos se encontraban en una zona alejada de los centros burocráticos de la corona, permaneciendo así ajenos a la observación de los cronistas (Bracco, "Dataciones

\footnotetext{
${ }^{16}$ Para explicar por qué esto es un problema, conviene aclarar algunos aspectos y clasificaciones de este tipo de fechado. Las muestras datadas a través del $14 \mathrm{C}$ debieron haber exhibido, en el momento del evento datado, un equilibrio isotópico entre su contenido de carbono y el del medio que las rodeaba. Ese intercambio se interrumpe en el momento a datar, de modo que el período que va desde ese momento al del análisis arqueológico (o recuperacional) es medible por el decaimiento radiactivo del $14 \mathrm{C}$. Los fechados de alta resolución son aquellos que ingresan al contexto arqueológico poco después de haber interrumpido el equilibrio con el medio; los de baja resolución son, obviamente, aquellos en los que medió un periodo largo entre su "muerte" y su ingreso al contexto (Bracco, "Dataciones 14C" 13). Para una descripción más detallada de los presupuestos científicos sobre los que se basa la datación por $14 \mathrm{C}$, puede verse Baeza.

17 También existe confirmación de esta contemporaneidad en algunos sitios excavados en lo que es hoy el departamento de Treinta y Tres (Prieto et al. 35).

18 Esta es la conjetura que ofrece Bracco ("Dataciones 14C" 15).
} 
14C" 15); lejanía en la cual se podría haber producido un proceso de aculturación (Bracco, "Desarrollo cultural" 13). Otra posibilidad razonable tiene que ver con los procesos de transculturación que se deben de haber producido entre las distintas etnias aborígenes que ocupaban el territorio (Cabrera, "El indígena y la conquista" 114). El proceso de interacción entre culturas nativas puede haber afectado de maneras que no conocemos a las etnias en contacto (entre las cuales pueden contarse a los charrúas, los constructores de cerritos y los guaraníes), ${ }^{19}$ afectando desde sus costumbres hasta sus prácticas económicas, pasando por su aspecto exterior o indumentario. También se ha manejado la hipótesis de que los cambios culturales que se fueron produciendo en la región forzaron a los pobladores de la zona a correrse hacia el interior, a terrenos más alejados de la costa (ídem 117). En el departamento de Tacuarembó (cerca del arroyo Yaguarí) se encuentran unos 56 cerritos (Sans 57), lo cual podría abonar la última de las explicaciones aventuradas. Sin embargo, a pesar de que se ubican, al igual que los cerritos del Este, en una zona baja, en las inmediaciones de cursos de agua, y de que el único mound excavado contiene restos funerarios, sus características (dimensiones que son considerablemente menores a las de los de la Laguna Merín, restos de cerámica menos numerosos) y su antigüedad (3170 $50 \mathrm{AP}$ ) parecen sugerir que desechemos esa posibilidad (ídem 57-58). ${ }^{20}$ De modo que habrá que esperar los resultados de las investigaciones en curso (a cargo de Camilla Gianotti) a fin de develar este otro enigma de la prehistoria.

Quisiera ahora llamar la atención sobre un aspecto relevante para el estudio de las prácticas del territorio prehistóricas: la existencia o ausencia de actividades agricultoras entre los grupos aborígenes. La opinión más recibida es que en el área que estudia el PRALM no hay vestigios que ameriten la afirmación de que los constructores de sitios con elevación hayan cultivado la tierra, ${ }^{21}$ pero tampoco puede afirmarse lo contrario (Bracco, "Desarrollo cultural" 10; López Mazz, "Aproximación al territorio" 71). Este es un elemento de sumo interés para un trabajo como el presente, cuyo objetivo es llamar la atención sobre las operaciones prehistóricas sobre el territorio, ya que el tratamiento al que se somete al suelo es, también, una de las marcas ignoradas a lo largo de la historia colonial y poscolonial de la región. La estructura palimpséstica del área se vería más complicada, aún, con este tipo de actividad que, si bien no es dable suponer revista un gran interés económico para el presente (como en el caso de las investigaciones de Erickson citadas

19) Si bien no es recomendable en todos los casos identificar restos arqueológicos con etnias históricas, existe abundante evidencia de utensilios guaraníes en los cerritos, especialmente en las capas más tardías, aunque puede decirse que su presencia es porcentualmente baja si la comparamos con el resto de los materiales encontrados (Cabrera, "El indígena y la conquista" 113). Lo cual plantea otro misterio: ¿qué pasó con los guaraníes que se instalaron en la zonas bajas de la zona del Este? ¿Se volvieron al territorio del Brasil actual? ¿Se transculturaron?

${ }^{20}$ Es interesante notar que la cerámica (aunque tosca, escasa y hallada en el nivel más superficial) tiene una antigüedad considerablemente mayor que la que normalmente se le atribuye al área (Sans $60)$.

${ }^{21}$ Por ejemplo, los estudios de polen que se han realizado no arrojaron evidencias de cultivo (López Mazz, Bracco, "Cazadores colectores" 12). En el caso del cerrito excavado en Tacuarembó, los estudios odontológicos apuntan a una dieta no agrícola (Sans 59), cosa que los diferencia con los del litoral, como ya veremos. 
al comienzo de este trabajo), sí lo tiene para la forma en cómo hoy imaginamos el territorio y su pasado. ${ }^{22}$

Lo que sí queda claro es que el territorio de lo que hoy es el Uruguay fue objeto de distintas ocupaciones y actividades que no pueden haber pasado desapercibidas a ninguno de los grupos que arribaron después, trátese de las etnias del tiempo histórico o de los conquistadores europeos. La actitud constante, durante siglos, de negación indirecta (nadie pronuncia a viva voz que los europeos y las etnias históricas fueron los primeros habitantes-ya que sería un disparate demasiado obvio-pero se guarda un silencio ignominioso sobre quienes ya estaban establecidos) de esta realidad, tiene como consecuencia una representación distorsionada de las interacciones humanas sobre un territorio que fue objeto de una larga lucha por su posesión y dominio. Una representación que sigue privando de historicidad y espesor a aquellas culturas que caen fuera del marco que define a la cultura occidental o, mejor aún, a aquellas culturas que se cayeron (o fueron expulsadas) del mapa. Restituir en parte ese espesor perdido puede ser un antídoto que permita al observador contemporáneo (especialmente al practicante de disciplinas humanísticas) ubicarse en una situación de enunciación pluritópica, capaz de admitir la existencia de más de una tradición cultural en el continente americano. Se trata del camino que, desde posicionamientos teóricos muy diferentes, tanto Mignolo como Kusch (citados al comienzo de este trabajo) han propuesto tomar. Una forma de interpretar esa propuesta es verla como un intento decidido de abrir el espectro de nuestros imaginarios sociales modernos a las culturas indígenas (tanto sobrevivientes como extinguidas), a sus prácticas y modos de entender el mundo. En el caso de estos últimos la tarea es mucho más difícil, debido tanto a la poca confiabilidad de las fuentes documentales (en lo relativo, por ejemplo, a las etnias históricas exterminadas) como a la total ausencia de ellas (como en el caso de los constructores de cerritos). En el primero de los casos, el estudio debe realizarse con mucho cuidado, filtrando los prejuicios ideológicos y culturales del observador europeo, leyendo sus descripciones y juicios a contrapelo, y todos los otros ejercicios (preventivos) de lectura a que se pueda apelar (Verdesio, La invención 15-24; "Las representaciones" 150-152). En el segundo, estamos ante un tipo de evidencia (la arqueológica) mucho más confiable. Pero tampoco es cuestión de confiar ciegamente en este tipo de investigación, ya que también presenta problemas, como el que sugiere la discrepancia entre el método disciplinario (análisis estático de una serie de objetos) y la realidad vital (de carácter dinámico en sus aspectos económicos y sociales) que se intenta exhumar (López Mazz, “Aproximación al territorio” 65). De modo que cuando se estudian grupos sociales extinguidos hay que tener en mente la advertencia que hace de Certeau con respecto a los mapas de itinerarios o actividades (en el trazado se pierde lo que realmente fue o existió: el acto mismo de pasar 97), pero que puede extrapolarse al caso de los estudios arqueológicos: lo que permanece (el material estudiable) es sólo un relicto

22 Los estudios más recientes sobre paleodieta arrojan resultados preliminares interesantes sobre la existencia de la agricultura (aunque incipiente) en algunas partes del territorio uruguayo. Todo parece indicar que en la costa del Río Uruguay - llamada Norte a) en el estudio que estoy citandodebió haber grupos humanos consumidores de maíz y, por lo tanto, una economía agricultora (Fregeiro 87-88). 
de una actividad humana que era mucho más compleja y que consistió en una práctica efectiva y determinada del espacio.

Esta advertencia debe completarse con otra, que está relacionada con la pregunta sobre la viabilidad de un proyecto que se plantee recuperar, simbólicamente, una alteridad que ya no existe, que ya no se encuentra, materialmente, entre nosotros. Está claro que el "cara a cara" de Levinas es imposible en una situación de este tipo, pero cabe señalar que ese modelo teórico tampoco garantiza en modo alguno la comprensión y representación adecuada del Otro. La razón es muy simple: el Otro es, pura y llanamente, una construcción discursiva que no puede dar cuenta del ser humano (o grupo de seres humanos), del individuo (o individuos) que se pretende representar (Cesareo 7-10, 167). Ese prójimo inalcanzable, esa realidad que se nos escapa en el preciso instante que intentamos aprehenderla y domesticarla, no se puede recuperar a través de una discursividad que produce a ese referente que llamamos "el Otro". En el caso de las etnias extinguidas (o exterminadas) el problema es todavía más claro, ya que el riesgo de incurrir en una especie de recurso prosopopéyico (esto es: atribuirle, unilateralmente, voluntad o voza un sujeto que, por muerto - es decir, por ser un habitante de la zona de lo invivible - es abyecto) es mayor aun y la representación inadecuada es un resultado casi seguro, debido a la ausencia de lo que se intenta representar. La arqueología (no la del saber, sino la de los objetos materiales), herramienta también insuficiente para la representación de aquel prójimo que construimos como Otro, tiene, sin embargo, una característica que no posee la mera especulación discursiva sobre la alteridad: nos enfrenta a cierta materialidad que no por inerte deja de ser palpable y autoevidente. Una materialidad que se nos presenta como relicto o fósil de actividades culturales, ofreciendo al observador, de este modo, la certeza de que alguien, en algún momento, en un lugar muy preciso, hizo algo. Tenemos la certeza de que alguien hizo los cerritos o los petroglifos, cazó cérvidos o pecaríes hoy inexistentes, que alguien (comunidades enteras) llevaron a cabo ceremoniales fúnebres cuyo significado se nos escapa, en un paisaje totalmente distinto al que hoy conocemos.

Pero otro efecto que tiene este estudio de actividades humanas fosilizadas es el de cuestionarnos la forma en que hoy vemos ese mismo espacio. En este sentido, es claro que nuestra mirada geográfica es un dispositivo occidental puesto al servicio de la colonización del territorio, que en América ha sido representado consuetudinariamente, según Turner, como salvaje. Es decir, como algo a dominar o a domesticar. ${ }^{23}$ Esta relación de hostilidad contra el paisaje americano (que es el fundamento que subyace a la ciudad letrada de que habla Rama) se manifiesta en una sobreestimación de la mirada globalizante del geógrafo, en tanto que opuesta al conocimiento corográfico del espacio que constituye el hábitat (y sus alrededores), característico de las sociedades aborígenes (Boelhower 50-51). ${ }^{24}$ Esta

23. Sobre el papel imperial de la cartografia en tanto que ciencia ancilar de la mirada geográfica, pueden consultarse los trabajos de J. B. Harley (por ejemplo, "Maps, Knowledge" 282; Maps and the Columbian encounter 24).

${ }^{24}$ Para una descripción de la diferencia entre geografía y corografía, es ilustrativo el siguiente pasaje de Alonso de Santa Cruz:

Geografía es una demostración o figura de toda la Tierra conocida con las partes más principales que de ella depende; y difiere de la corografía porque ésta, describiendo todos los lugares particularmente, 
perspectiva colonial que todavía domina nuestra forma de imaginar el espacio que habitamos es posible, entre otras cosas, gracias a la metáfora de la página en blanco, que borra de nuestro imaginario toda traza de prácticas espaciales que no tengan o hayan tenido como agentes a sujetos occidentales. La deshistorización del territorio, su deshumanización, son consecuencias que dejan su impronta en nuestro formato cognitivo, en nuestra cultura, en nuestra episteme. Una forma de combatir esta situación es abrir un intersticio en nuestro imaginario que permita, de una vez por todas, no sólo reconocer las prácticas territoriales anteriores a las operadas por el sujeto occidental, sino también la presencia que aquéllas tienen en nuestro paisaje presente. Porque aquel paisaje prehistórico, tan distinto al que hoy conocemos es, de alguna forma, parte de éste. Al menos lo es desde una perspectiva diacrónica que conciba al paisaje como una entidad que evoluciona, que se transforma, ya sea por causa de fenómenos geológicos o climáticos, o por la intervención del ser humano. La materialidad de las marcas, cicatrices y mutaciones ostentadas por el paisaje, nos recuerda que algunas de ellas son de origen antrópico y que por allí hubo una serie de prójimos actuando, modificando el entorno; es decir, viviendo. El incorporar esas marcas a nuestro imaginario es una forma, me parece, de incorporar a ese aborigen que nos empeñamos en construir, discursivamente, como el Otro. Es volverlo parte de nuestro horizonte cognitivo y, de alguna manera, de nosotros mismos. ${ }^{25}$

Si lo que caracteriza a toda cultura es, como nos recuerda Turner, una relación muy especial con la tierra en que se desarrolla (xxi), es claro que la forma en que vivimos y pensamos será profundamente afectada por la forma en que percibimos o concebimos el territorio. Si ignoramos las huellas dejadas (y la autoría de las modificaciones operadas) en la tierra que practicamos, tendremos una visión distorsionada del suelo que pisamos y, lo que es más grave (por soberbio), ignoraremos que, en realidad, se trata de un palimpsesto al que, modesta y casi inadvertidamente, estamos contribuyendo a enriquecer.

Varias veces por semana debo pasar por el parque de estacionamiento que está a la salida de Prescott Hall (edificio de LSU donde trabajo), llamado Indian Mounds. El nombre, previsiblemente, se debe a que allí se erigen dos montículos artificiales de origen antrópico. Sobre su superficie y alrededores, los estudiantes desarrollan todo tipo de actividades: toman un refresco o almuerzan, juegan o simplemente conversan. La multitud de acciones cotidianas ( $y$ a veces ruidosas) a través de las cuales estos estudiantes operan sobre esa elevación creada hace cientos de años por una cultura desaparecida, contrastan con el silencio que guarda, para nuestro imaginario occidental, el lugar sobre el que se desarrollan. Sin embargo (y sin caer en mecanismos prosopopéyicos) es posible intentar hacer, de alguna manera, "hablar" a ese pedazo de tierra, a través del interrogatorio

manifiesta cada uno por sí y lo que en ellos se contiene, describiendo hasta las más pequeñas partes que en ellos se hallan, como son puertos, aldeas, vueltas de rios y cosas de esta cualidad;... el fin de la corografia consiste en representar sucesivamente una parte del todo, como queriendo pintar o remedar un ojo o una oreja, pero la geografía tiene atención al todo conforme a su proporción, como si quisiese pintar toda la cabeza (203).

${ }_{25}$ Esta operación de reconocimiento del Otro en nuestra cotidianeidad (es decir, su participación en nuestro presente) puede ser, acaso, un antídoto contra el "denial of coevalness" mediante el cual ponemos distancia entre el aborigen (entendido como objeto de estudio que vive en un estadio de evolución distinto al nuestro) y nosotros en tanto que observadores (Fabian). 
arqueológico y de una operación hermenéutica de carácter pluritópico. No lograremos, obviamente, una verdadera conversación con el sitio, pero será posible al menos obtener una certeza: en ese mismo espacio que nosotros practicamos, cientos de años atrás, generaciones de individuos que nos empeñamos en olvidar, desarrollaron una serie de actividades, de las cuales sólo algunas (la construcción del cerrito, por ejemplo) nos son conocidas. No sabemos demasiado sobre algunas de las otras acciones que aquéllos llevaban a cabo en ese sitio, pero una cosa es segura: algo hacían. Los resultados y su materialidad, que forman parte de nuestro entorno, de nuestro hábitat, están a la vista. Sólo hay que querer verlos.

\section{BibliogRAFIA}

Baeza, Jorge. "Los fechados radiocarbónicos de Salto Grande". Estado actual de las investigaciones arqueológicas en el Uruguay. Parte 1. Montevideo: Centro de Estudios Arqueológicos, 1985. 20- 24.

Barrios Pintos, Aníbal. Los aborígenes del Uruguay. Montevideo: Linardi y Risso, 1991. "Los indígenas del tiempo histórico". Artigas: de los aborígenes cazadores al tiempo presente. Tomo I. A. Barrios Pintos, ed. Montevideo: Ministerio de Educación y Cultura, 1989. 25- 45.

Beovide, Laura. “Análisis de los restos arqueofaunísticos de la 'Casa del Diablo,' San Miguel, Rocha". Arqueología en el Uruguay. VIIICongreso Nacional de Arqueología Uruguaya. Mario Consens, José María López Mazz y María del Carmen Curbelo, eds. Montevideo, 1995. 54- 64.

Boelhower, William. Through a Glass Darkly: Ethnic Semiosis in American Literature. New York y Oxford: Oxford University Press, 1987.

Borrero, Luis Alberto y José Luis Lanata. "Arqueología espacial en Patagonia: Nuestra perspectiva". Análisis espacial en la arqueología patagónica. Luis Alberto Borrero y José Luis Lanata, eds. Buenos Aires: Búsqueda de Ayllu SRL, 1992. 145-162.

Bracco, Roberto. "Dataciones 14C en sitios con elevación". Revista Antropología 1/1 (1990): $11-17$.

"Desarrollo cultural y evolución ambiental en la región Este del Uruguay". Ediciones del Quinto Centenario. Vol. I. Renzo Pi Hugarte et al. Montevideo: Universidad de la República, 1992. $1-22$.

Cabrera, Leonel. "Presentación al Simposio 'Etnohistoria”". Arqueología en el Uruguay. VIII Congreso Nacional de Arqueología Uruguaya. Mario Consens, José María López Mazz y María del Carmen Curbelo, eds. Montevideo, 1995. 221- 224. "El indígena y la conquista en la cuenca de la Laguna Merín". Ediciones del Quinto Centenario. Vol. I. Renzo Pi Hugarte et al. Montevideo: Universidad de la República, 1992. 97- 122.

Panorama retrospectivo y situación actual de la arqueología uruguaya. Montevideo: Universidad de la República, 1988. 
Castellano, Ana y Mariano Consens. "Aspectos formales de la clasificación arqueológica: Un aporte del arte rupestre". Arqueología en el Uruguay. VIII Congreso Nacional de Arqueología Uruguaya. Mario Consens, José María López Mazz y María del Carmen Curbelo, eds. Montevideo, 1995. 134- 141.

Cavellini, Susana. "Síntesis etnohistórica". Misión de rescate arqueológico. Salto Grande. República Oriental del Uruguay. Tomo I. Montevideo: Ministerio de Educación y Cultura, 1987. 81-142.

Certeau, Michel de. The Practice of Everyday Life. Steven Rendall, trad. Berkeley: University of California Press, 1984.

The Writing of History. Tom Conley, trad. New York: Columbia University Press, 1988.

Cesareo, Mario. Cruzados, mártires y beatos. Emplazamientos del cuerpo colonial. West Lafayette, IN: Purdue University Press, 1995.

Consens, Mariano. "Arte Rupestre en el Uruguay". Estado actual de las investigaciones arqueológicas enel Uruguay. Parte I. Montevideo: Centro de Estudios Arqueológicos, 1985. $62-72$.

"Arte rupestre y mobiliar". Artigas: de los aborígenes cazadores al tiempo presente. Tomo I. A. Barrios Pintos, ed. Montevideo: Ministerio de Educación y Cultura, 1989. 18- 24.

"Evaluación de un sitio con grabados rupestres. H-TA-CR I, Colonia Rubio, Salto, Uruguay”. Arqueología en el Uruguay. VIIl Congreso Nacional de Arqueología Uruguaya. Mario Consens, José María López Mazz y María del Carmen Curbelo, eds. Montevideo, 1995. 172- 192.

Curbelo, Carmen, Leonel Cabrera, Fusco Nelsys, Elianne Martínez, Roberto Bracco, Jorge Femenías, José M. López. "Sitio CH2DO1, área de San Miguel. Depto. de Rocha, R. O. del Uruguay. Estructura de sitio y zonas de actividad". Revista do CEPA 17/20 (1990): 333-344.

Curbelo, Néstor. "El enigma de nuestro pasado". Posdata 106 (1996): 13- 21.

Dubelaar, C. N. South American and Caribbean Petroglyphs. Dordrecht and Riverton: Foris Publications, 1986.

Erickson, Clark. "The Social Organization of Prehispanic Raised Field Agriculture in the Lake Titicaca Basin". Economic Aspects of Water Management ind the Prehispanic New World. Research in Economic Anthropology. Supplement 7. Vernon Scarborough y Barry Isaac. eds. Greenwich, CT y London: Jai Press, 1993. 369- 426.

"Prehistoric Landscape Management in the Andean Highlands: Raised Field Agriculture and its Environmental Impact". Population and Environment 13/4 (1992): 285-300.

Fabian, Johannes. Time and the Other. How Anthropology Makes Its Object. New York: Columbia University Press, 1983.

Femenías, Jorge. "Amontonamientos artificiales de piedras en cerros y elevaciones de nuestro territorio". Revista Antropológica 1/1 (1983): 13- 16.

Femenías, Jorge, José M. López, Roberto Bracco, Leonel Cabrera, Carmen Curbelo, Nelsys Fusco, Elianne Martínez. "Tipos de enterramiento en estructuras monticulares 
('cerritos') en la región de la cuenca de la Laguna Merín (R. O. U.)". Revista do CEPA 17/20 (1990): 345- 356.

Fregeiro, Ana Inés. "Trabajo final de licenciatura. Antropología, opción Arqueología". Montevideo: Facultad de Humanidades, Universidad de la República, 1966.

Harley, J. B. Maps and the Columbian Encounter. Milwaukee: The Golda Meir Library, 1990.

"Maps, Knowledge and Power". The Iconography of Landscape. Denis Cosgrove y Stephen Daniels, eds. Cambridge: Cambridge University Press, 1988. 277-312.

Kusch, Rodolfo. El pensamiento indigena y popular en América. Buenos Aires: Hachette, 1977 [1970].

López Mazz, José M. "La reconstrucción del pasado, la identidad nacional y la labor arqueológica: el caso uruguayo". Arqueología en América Latina hoy. E. Politis, ed. Bogotá: Biblioteca Popular, 1992. 167- 175.

"Aproximación a la génesis y desarrollo de los cerritos de la zona de San Miguel (Departamento de Rocha)". Ediciones del Quinto Centenario. Vol. I. Renzo Pi Hugarte et al. Montevideo: Universidad de la República, 1992. 76-96.

"Aproximación al territorio de los "constructores de cerritos"'. Arqueología en el Uruguay. VIII Congreso Nacional de Arqueología Uruguaya. Mario Consens, José María López Mazz y María del Carmen Curbelo, eds. Montevideo, 1995. 65-78.

"El fósil que no guía y la formación de los sitios costeros". Arqueología en el Uruguay. VIII Congreso Nacional de Arqueología Uruguaya. Mario Consens, José María López Mazz y María del Carmen Curbelo, eds. Montevideo, 1995. 92-105. "Trabajos en tierra y complejidad cultural en el Rincón de los Indios". 1996(Xerox) $1-14$.

López Mazz, José M. y Roberto Bracco. "Las sociedades prehistóricas: viejas y nuevas aproximaciones". Anales del $V I^{O}$ encuentro nacional y $\mathrm{IV}^{\circ}$ regional de historia I/ 1 (1989): 107-114.

"Relación hombre-medio ambiente en las poblaciones prehistóricas de la zona Este del Uruguay". Archaeology and Environment in Latin America. Omar OrtizTroncoso y Thomas van der Hammen, eds. Amsterdam: Universitat van Amsterdam, 1992. 259- 282.

"Cazadores colectores de la cuenca de la Laguna Merín: Aproximaciones teóricas y modelos arqueológicos". 47o Congreso Internacional de Americanistas, New Orleans, 1991 (Xerox): 1-15.

Maggi, Carlos. Artigas y su hijo el caciquillo. Montevideo: Fin de Siglo, 1992.

Maturana, Humberto y Francisco Varela. Autopoiesis and Cognition: The Organization of the Living. Dordrecht, Boston and London: D. Reidel Publishing Company, 1980.

Mignolo, Walter D. "Colonial Situations, Geographical Discourses and Territorial Representations: Toward a Diatopical Understanding of Colonial Semiosis". Dispositio 14/36-38 (1989): 93-140.

"La grafía, la voz y el silencio: las Relaciones Geográficas de Indias en el contexto de las letras virreinales". Insula 45/522 (Junio 1990): 11-12.

"Occidentalización, imperialismo, globalización: herencias coloniales y teorías postcoloniales". Revista Iberoamericana 170-171 (1995): 27-40. 
Peláez Castello, Emilio. "Apuntes sobre arte rupestre uruguayo". Hoy Es Historia 3/18 (1986): 66-73.

Pérez de Micou, Cecilia; Cristina Bellelli y Carlos Aschero. "Vestigios minerales y vegetales en la determinación del territorio de explotación de un sitio". Análisis espacial en la arqueología patagónica. Luis Alberto Borrero y José Luis Lanata, eds. Buenos Aires: Búsqueda de Ayllu SRL, 1992. 53-82.

Pi Hugarte, Renzo. Los indios del Uruguay. Madrid: Mapfre, 1993.

Prieto, O. et. al. "Información preliminar sobre investigaciones arqueológicas en el Departamento de Treinta y Tres, R. O. U.”. Publicaçoes Avulsas. 1. S. Leopoldo: Instituto Anchietano de Pesquisas, 1970.

Rama, Angel. La ciudad letrada. Hanover, NH: Ediciones del Norte, 1984.

Sans, Mónica. "Arqueología de la región del Arroyo Yaguarí (Departamento de Tacuarembó): Informe preliminar". Estado actual de las investigaciones arqueológicas en el Uruguay. Parte 1. Montevideo: Centro de Estudios Arqueológicos, 1985. 57-61.

Santa Cruz, Alonso de. Alonso de Santa Cruz y su obra cosmográfica. Mariano Cuesta Domingo, ed. Madrid: Consejo Superior de Investigaciones Científicas, 1983.

Tainter, Joseph. "Mortuary Practices and the Study of Prehistoric Social Systems". Advances in Archaeological Method and Theory. Vol. I. Academic Press, 1978.

Taussig, Michael. Shamanism, Colonialism and the Wild Man. A Study in Terror and Healing. Chicago and London: University of Chicago Press, 1987.

Turner, Frederick. Beyond Geography. The Western Spirit Against the Wilderness. New Brunswick, NJ: Rutgers University Press, 1994 [1983].

Verdesio, Gustavo. La invención del Uruguay. La entrada del territorio y sus habitantes a la cultura occidental. Montevideo: Graffiti; Trazas, 1996.

"Las representaciones territoriales del Uruguay colonial: Hacia una hermenéutica pluritópica". Revista de Crítica Literaria Latinoamericana 23/46 (1997): 135-161.

Vidart, Daniel. El mundo de los charrúas. Montevideo: Ediciones de Banda Oriental, 1996.

"Los cerritos de los indios" del Este uruguayo. Montevideo: Ediciones de Banda Oriental, 1996.

Vorsey, Louis de, Jr. "Silent Witnesses: Native American Maps". The Georgia Review 46/4 (1992): 709-726. 